\title{
Sharing of tacit knowledge in volunteer Portuguese firefighters - paths to diagnosis
}

\begin{abstract}
Purpose - focusing on the study of tacit knowledge sharing in nonprofit organizations (NPOs) in Portugal and taking as a case study the Portuguese voluntary firefighters, we set as objectives, identify the most relevant factors for sharing tacit knowledge and identify the types of barriers most prevalent to such sharing in these organizations.

Design / methodology / approach - a literature review on tacit knowledge sharing allowed the identification of indicators and barriers to the sharing of this knowledge. This was followed by a mixed methodology that combines qualitative and quantitative techniques through questionnaires and interviews, whose treatment allowed to determine the indicators that influence each of these factors and which types of barriers.

Findings - Three factors have been identified that lead to the sharing of tacit knowledge within these organizations: organizational culture, individual characteristics, and organizational structure. Four typologies of barriers were identified: communicational, technological, personal and resource or infrastructure.

Research limitations / implications - The present research focuses exclusively on the sharing of tacit knowledge, not considering other forms of knowledge. As a case study, although with heterogeneous organizations, the same cannot be replicated to different realities.

Originality / Value - Studies in this area, targeting NPOs are scarce, as opposed to what is happening in the private and public sectors. The option of a case study of organizations such as the Portuguese fire brigades (FBs), unique in their action and identity, accompanies the need increasingly recognized by society, in enabling these organizations of competencies for the best possible performance, in the face of tragic events that have occurred in recent years in Portugal.
\end{abstract}

KEYWORDS: Tacit knowledge sharing, volunteer firefighters, non-profit organizations.

\section{INTRODUCTION}

We live days marked by rapid and constant changes in society. The organizations that compose it are increasingly characterized by competitiveness and greater pressure to fulfil their missions, obeying the highest quality standards. The ability of organizations to carry out their missions effectively depends more and more on their ability to mobilize the knowledge they hold for the sake of organizational learning that provides them with a continuous gain of skills (Sohi and Matthews, 2019).

Research in the field of knowledge management has focused mainly on the public and private sectors. Studies related to knowledge management in non profit organizations (NPOs), carried out to date are important contributions, but still scarce (Ragsdell, 2016). The relevance of deepening knowledge management research directed at the third sector becomes even more relevant if we consider that, according to Fotler (1981), organizations that operate in this sector operate in very dynamic and complex contexts, whose studies can lead valuable reflections on organizational behavior.

However, the sharing of tacit knowledge within these organizations, despite the recognition of the benefits that can result from it, is not something that is easy to establish as a regular practice.

In addition to scientific interest, the study finds other motivations. During 2017, two major fire events took place in Portugal, responsible for more than 500 thousand hectares of burnt area, the first between the 17th and 24th of June in the Municipalities of Pedrogão Grande, Castanheira de Pêra, Ansião, Alvaiázere, Figueiró dos Vinhos, Arganil, Góis, Penela, Pampilhosa da Serra, Oleiros and Sertã, where 64 people died and where 490 homes and 50 industrial units burned, and the second, between 14 and 16 October, over 30 municipalities in the central region of Portugal, where 48 people died and where 521 industrial units burned, 
responsible for 4500 jobs. These events refocused the importance of fire brigades (FBs) activity in the field of civil protection and launched a series of reflections with civil society, which are related to the need to provide these operational staff with greater knowledge, qualification and the need to adopt best practices. governance of the Portuguese forest. It is important to mention that in Portugal there is no other type of organization with operational activities in the area of civil protection, with similar characteristics. Among the several peculiarities that give it this uniqueness, the following stand out: the fact that the set of its human resources is composed of a combination of voluntary elements and salaried employees who provide the minimum daily operational services; of being the volunteer firefighters to ensure the night and weekend duty schedules; that there is an increase in intervention and availability of these voluntary elements in the summer seasons, with a clear decrease in service in the remaining seasons of the year; the hierarchical structure follows a paramilitary regime, but which may include at the top of its pyramid firefighters who only perform functions on a voluntary basis, which means that in most cases, they are elements with a voluntary link to coordinate operations where include elements with a salary link.

Thus, the present article presents the results of a research on tacit knowledge sharing in Portuguese FBs, assessing the prevalence of the main indicators mentioned in the literature, indicating the factors and barriers that determine the success or failure of this sharing.

The article begins with a summary that includes essential information about the objectives, the methodological approach, the main conclusions, the limitations of the research, and the originality or value of the research. The following is a brief introduction to the theme and keywords. Next, the theoretical framework is presented, with emphasis on the tacit knowledge sharing indicators and their relevant factors. The next point deals with the presentation and discussion of the results. Finally, we present the conclusions and recommendations for future studies.

\section{THEORETICAL FRAMEWORK}

The theoretical framework contemplates an approach to the specificity of sharing within what is the management of tacit knowledge, the indicators and the barriers to that sharing.

\subsection{Tacit knowledge and its sharing}

Tacit knowledge refers to a type of knowledge whose description or communication is not easy and reflections on its importance only gained visibility with Polanyi's $(1962,1966)$ studies. For Nonaka (1994), explicit knowledge is codified and can be easily communicated and transferred, and can be presented in the form of manuals, plans, procedures, among others. In contrast, tacit knowledge is implicit, it is difficult to conceptualize, it is subjective and composed by the experiences of the individual (Castellani et al, 2019). According to Dalkir (2005), Haldin-Herrgard (2000), it is possible to gather a set of identifying properties about what is tacit knowledge. For these authors, tacit knowledge resides in human minds and in relationships between individuals in an unstructured form, difficult to see, codify, estimate, formalize, investigate, describe, capture or communicate with precision, being acquired through the sharing of experiences, observation, imitation or by "face-to-face" interaction. It is, therefore, a knowledge rooted in the action, procedures, commitments, values, and emotions that enable the individual to better deal with exceptional and unexpected situations. Tacit knowledge is subconscious, personal, difficult to articulate, perceived, unconscious, based on experience, shared through conversation and imbued with stories (Polanyi, 1966). It is based on insights and understandings, judgments, assumptions, relationships, norms and values, and organizational culture. In this respect, Davenport and Prusak (2000) describe some of the characteristics of tacit knowledge that make their sharing a challenge. For these authors, tacit knowledge is difficult to code in documents or databases; is developed and internalized over a long period of time and within a specific cultural environment; this tacit knowledge-taking process is not always a conscious and some of this tacit knowledge may not even be capable of representation outside the human mind.

\subsection{Tacit knowledge sharing indicators}


Thus, in order to be able to ascertain the existence of tacit knowledge sharing within an organisation, it was possible to compile a set of indicators that are echoed in the literature and that we adopted for the present study (Oliveira and Pinheiro, 2019).

1. Individual time management; 2. Shared language; 3. Mutual confidence; 4. Relational network; 5. Hierarchy; 6. Recognition and reward; 7. Type of training for the task; 8. Transmission of knowledge; 9. Storage of knowledge; 10. Power; 11. Environment favourable to questioning; 12. Type of knowledge valued: 13 . Communication; 14 . Physical space.

Once the indicators are presented, it is important to reflect on factors relevant to the sharing of tacit knowledge in which these indicators can be grouped, such as the organisational culture, the individual characteristics and the organisational structure.

First, people in an organisational context, interact with each other and the organisational context or culture where this occurs, according to Lemos and Joia (2012), is determinant for the sharing of tacit knowledge. Creating a culture conducive to their sharing is, according to Davenport and Prusak (1998), increasingly a critical success factor for organisations. Organisational culture, according to Jeng and Dunk (2013), can be defined as a unique system within which certain values and behaviors are shared. In a context of knowledge sharing, for Davenport and Prusak (1998), organisational culture is even a determining factor to consider, since it will function as the "infrastructure" where this sharing will take place. Jeng and Dunk (2013) even argue that organisational change is sometimes necessary, giving as an example the paradigm shift, centering rewards on knowledge sharing attitudes, to the detriment of rewards for individual performance.

On the other hand, and according to the same authors, the individual component such as experience, reflection, internalization or talent is equally decisive for this sharing. Since, according to Eppler and Sukowski (2000), it is the people who are at the center of the creation of organisational knowledge, individual characteristics are also a critical factor to tacit knowledge sharing. In this respect, Nonaka and Takeuchi (1995) tell us that updating knowledge within an organisation can be achieved through the admission of new people with specific knowledge or skills that can be shared later. For Lemos and Joia (2012), the more the person is open to others, the more likely they are to be willing to share tacit knowledge, since their action will be oriented to spend more time with their colleagues, to deposit more confidence in their relationship with them, greater appreciation of peers' insights and heuristics, and greater interest in developing the common language of other professionals.

Finally, the organisational structure, which according to Ichijo et al. (1998) and Castellani et al. (2019), may encourage or inhibit knowledge sharing, it must also be considered as a determinant factor for the sharing of tacit knowledge. For these authors, it is important that the organisational structure is flexible enough to encourage the sharing of knowledge among those within the hierarchy. According to Nonaka and Takeuchi (1995) and O'Dell and Grayson (1998), flexible, less formal and less centralizing organisational structures are more conducive to sharing tacit knowledge.

\subsection{Barriers to tacit knowledge sharing}

However, if the analysis of the indicators is possible to determine the factors that influence the sharing of tacit knowledge, the role of the barriers to this sharing must also be considered and can have very different origins. According to Riege (2007), the identification and recognition of the existence of barriers to knowledge sharing is even an important factor for the success or failure of a knowledge management strategy. It is possible to determine the existence of several potential barriers within an organisation, which are echoed in the literature, such as barriers at the personal, communicational, technological and resource and infrastructure levels.

At the communicational level, according to Davenport and Prusak (1998), an effective communication, whether in a verbal or written form, is fundamental for an effective sharing of tacit knowledge, so that its absence constitutes an important barrier. For Riege (2007), the lack of contacts and interactions between knowledge sources and recipients is another possible barrier to this knowledge sharing. For Jóia and Lemos (2010) organisations with bureaucratic and hierarchical characteristics are not flexible, and these characteristics stand as barriers to communication to this sharing. For Holste and Fields (2010) and Reige 
(2005), internal competitiveness, high turnover, limited resources, lack of transparency, lack of qualified and experienced staff can also constitute barriers to good communication.

At a technological level, Mohajan (2016) has changed the way organisations operate and how they have the means to access and provide instant access to information and data over long distances. However, for the same author, technology is also a challenge, in the sense that it sometimes makes it difficult to apply and manage tacit knowledge. For authors such as Awad and Ghaziri (2007), organisations that only invest in systems and processes of information and communication technologies become excessively dependent on this technology and invest little in the individual knowledge of their collaborators which can jeopardize the management of tacit knowledge. Riege (2005) also presents a set of technological barriers to the sharing of tacit knowledge, such as the insufficiency of these to respond to the tasks requested, their inadequacy to the needs of the members of the organization and in relation to the need to communicate with the elements of the organization, the complexity of its use by the elements of the organization, its inability to enhance the performance of the elements of the organization and poor technical support to maintain them.

At the personal level, we can say that characteristics such as temperament, attitude, or interpersonal skills, according to Awad and Ghaziri (2007), can make it difficult to share tacit knowledge. For the same authors, it may happen that certain elements of the organisation avoid sharing their knowledge because of the risk of weakening their work position against other elements. For Sveiby and Simons (2002), there are some other possible barriers or personal barriers to this sharing, such as age, gender, level of education, experience in the job or position it holds. For Riege 2005, the low perception of the tacit knowledge that one possesses and that others may need should be considered as an obstacle to this sharing. According to Nonaka and Takeuchi (1995) and Michailova and Husted (2003), differences in culture of origin, race, and value systems should also be considered as important personal barriers. For O'Dell and Grayson (1998), the perceived lack of a reward and recognition system can lead to demotivation of people and hamper this sharing. Still, to Holste and Fields (2010), the inability to convey a sense of trust to others and a lack of trust in the other elements of the organisation fosters interpersonal relationships that are obstacles to sharing tacit knowledge.

At the level of resources and infrastructures, for Probst et al. (2000), the offices or departments of organisations tend to be organized according to management hierarchies or seniority rather than arranged in a way that promotes the closeness of people who need to work together regularly. For Gold et al. (2001), it is important that work processes provide enough space to allow people time to generate and share knowledge and then identify those who may be interested in sharing it. According to these authors, a deficiency of formal and informal spaces where employees can interact often creates barriers to tacit knowledge sharing.

\section{DATA COLLECTION AND METHODOLOGY}

Based on indicators and barriers of tacit knowledge management, a mixed methodology was followed. A questionnaire was developed, based on this indicators and barriers, to sharing tacit knowledge, found in the literature (Oliveira and Pinheiro, 2019), that sought to determine the perception of the respondents about the prevalence of each of the indicators and barriers under analysis (table 2. and 3.). Each question aimed to determine the degree of agreement on the prevalence of an indicator or barrier to tacit knowledge sharing. Respondents were firefighters who anonymously and voluntarily adhered to the questionnaire. In line with the presented, the sample perfected a total of 380 firemen. In order to identify and eliminate possible problems of the questionnaire, a pre-test was carried out with 32 firefighters from Brasfemes FB. Once the data of the 380 respondents were collected during the month of September 2018, the reliability or internal consistency of the indicators and barriers was verified by calculating Cronbach's alpha. We then proceeded to an exploratory factorial analysis in order to obtain a reduction of data through its grouping into factors, thus, it is possible to diagnose the leading factors and the groups of barriers that effectively influence this phenomenon and to determine which indicators influence each factor conducive to the sharing of tacit knowledge within FBs. Initially, the Bartlett sphericity test was applied and the Kaiser-Meyer-Olkin (KMO) test statistic was obtained, both tests verifying the adequacy of the data to the factorial analyzes. Then, the principal component analysis (PCA) method was applied based on the correlation matrix, in order to obtain a minimum number of factors responsible for the maximum data variance. The minimum number 
of factors related to the indicators was fixed using the eigenvalues, and only the factors with eigenvalues greater than 1 were maintained, according to the latent root method. The same exercise was applied to the calculation of the main groups of barriers. Finally, the Varimax orthogonal rotation method was used to simplify the columns of the factorial matrix, providing a clearer separation of the factors.

Due to the wealth of information that volunteer fire brigade commanders could bring to the investigation, they were considered for interview purposes. A set of semi-structured interviews was carried out, with a pre-approved script, but with sufficient openness to change the order of the questions, applied to FB commanders of the central region of Portugal, in order to ascertain and confirm the prevalence of tacit knowledge and the main barriers associated with this sharing. Table 1. presents the profile of each interviewee.

Table 1. Profile of each interviewee.

\begin{tabular}{|c|c|c|c|c|c|c|c|}
\hline FBs & $\begin{array}{c}\text { Nome do } \\
\text { Comandante }\end{array}$ & Idade & Escolaridade & Categoria & Quadro & $\begin{array}{l}N^{o} \text { total } \\
\text { de anos } \\
\text { serviço }\end{array}$ & $\begin{array}{c}N^{0} \text { anos } \\
\text { serviço na } \\
\text { função }\end{array}$ \\
\hline Brasfemes & Acácio Monteiro & 63 & $12^{\circ}$ ano & Comandante & Comando & 30 & 11 \\
\hline Ol. Hospital & Emídio Camacho & 54 & $12^{\circ}$ ano & Comandante & Comando & 35 & 17 \\
\hline Anadia & Bruno Almeida & 37 & Mestrado & Comandante & Comando & 14 & 1 \\
\hline Góis & Jody Rato & 43 & Licenciado & Comandante & Comando & 29 & 1 \\
\hline Loriga & António Alves & 48 & $12^{\circ}$ ano & Comandante & Comando & 28 & 25 \\
\hline Penela & António Lima & 48 & $12^{\circ}$ ano & $2^{\circ}$ Comandante & Comando & 30 & 12 \\
\hline Guarda & Paulo Sequeira & 47 & Licenciatura & Comandante & Comando & 32 & 6 \\
\hline Miranda Corvo & Fernando Rodrigues & 53 & Licenciatura & Comandante & Comando & 36 & 18 \\
\hline
\end{tabular}

Source: By the authors

The technique used to select the sample was the snowball technique, and eight interviews were carried out between July 12 and August 24, 2018.

Figure 1. Sequence of interviews conducted under the technique of snowball sampling.

\begin{tabular}{|c|c|c|c|c|c|c|c|}
\hline $\begin{array}{c}\text { 1st } \\
\text { interview }\end{array}$ & $\begin{array}{c}\text { 2nd } \\
\text { interview }\end{array}$ & $\begin{array}{c}\text { 3rd } \\
\text { interview }\end{array}$ & $\begin{array}{c}\text { 4th } \\
\text { interview }\end{array}$ & $\begin{array}{c}\text { 5th } \\
\text { interview }\end{array}$ & $\begin{array}{c}\text { 6th } \\
\text { interview }\end{array}$ & $\begin{array}{c}\text { 7th } \\
\text { interview }\end{array}$ & $\begin{array}{c}\text { 8th } \\
\text { interview }\end{array}$ \\
\hline \multirow{4}{*}{$\begin{array}{l}\text { Brasfemes } \\
12.07 .2018\end{array}$} & & & & $\begin{array}{l}\text { Loriga } \\
\text { 13.08.2018 }\end{array}$ & & $\begin{array}{l}\text { Guarda } \\
20.08 .2018\end{array}$ & \\
\hline & $\begin{array}{l}\text { Oliveira do } \\
\text { Hospital } \\
\text { 06.08.2018 }\end{array}$ & & $\begin{array}{l}\text { Góis } \\
\text { 10.08.2018 }\end{array}$ & & & & \\
\hline & & & & & $\begin{array}{l}\text { Penela } \\
14.08 .2018\end{array}$ & & $\begin{array}{l}\text { Miranda do } \\
\text { Corvo } \\
\text { 24.08.2018 }\end{array}$ \\
\hline & & $\begin{array}{l}\text { Anadia } \\
\text { 07.08.2018 }\end{array}$ & & & & & \\
\hline
\end{tabular}

Source: By the authors

\section{PRESENTATION AND DISCUSSION OF RESULTS}

The presentation of results of the present study addresses, first, the data on the factors of sharing and, later, the barriers to the sharing of tacit knowledge, combining information of a quantitative and qualitative nature.

\subsection{Factors of tacit knowledge sharing in FBs}

Once the factorial analysis of the data obtained through the responses to the questionnaires by firefighters was carried out, as described in the previous point, it was possible to find the structure of factors relevant 
to the transfer of tacit knowledge, according to table 2. From the content analysis of the interviews, it is possible to perceive that there is a correspondence of the collected testimonies to the perceived reality regarding these 3 factors.

Table 2. Rotated matrix component of the tacit knowledge sharing indicators in FBs.

\begin{tabular}{|c|c|c|c|}
\hline \multirow[t]{2}{*}{ Indicators } & \multicolumn{3}{|c|}{ Factors } \\
\hline & $\begin{array}{c}1 \text { - Organisational } \\
\text { culture }\end{array}$ & $\begin{array}{l}2 \text { - Individuals } \\
\text { characteristics }\end{array}$ & $\begin{array}{c}\text { 3-Organisational } \\
\text { structure }\end{array}$ \\
\hline 11. Favorable environment for questioning &, 736 & & \\
\hline 12. Kind of valued knowledge & ,721 & & \\
\hline 13. Communication & 666 & & \\
\hline 14. Phisical space &, 591 & & \\
\hline 10. Power &, 537 & & \\
\hline 8. Transmission of knowledge &, 535 & & ,503 \\
\hline 6. Recognition and reward & 451 & 418 & \\
\hline 3. Mutual trust & & ,793 & \\
\hline 2. Common language & & ,760 & \\
\hline 1. Individual time management & &, 754 & \\
\hline 5. Hierarchy & & & ,791 \\
\hline 4. Relationship network & & 469 & 637 \\
\hline 9. Knowledge storage & & & 624 \\
\hline 7. Type of training for the task & ,538 & &, 557 \\
\hline
\end{tabular}

Following this, it is important to say that the current organisational culture is the first factor found by this study and is defining the existence of a favorable environment for questioning and, consequently, tacit knowledge sharing, where, each element can openly acknowledge its ignorance on certain subjects and where constructive criticism is well accepted. It is the organisational culture that emphasizes the type of knowledge valorized, favoring forms of tacit knowledge such as personal skills or intuitions, to the detriment of standardized training actions and non-differentiating, where logic or rationality prevail as dominant methods. It is also in the organisational culture that the most prevalent forms of communication are found. The promotion of personal and informal conversations is very valid as a form of communication for tacit knowledge sharing, as it allows the use of body language, the demonstration of personal and obtaining optimal and immediate feedback.

It is deeply rooted in the organisational culture the promotion or inhibition of this type of interactions between the people who constitute it. Closely related to the form of communication are the physical spaces suitable for the same purpose. Spaces open to interactions that foster team collaboration and enable experimentation are conducive to sharing tacit knowledge. The availability of physical or even virtual spaces, such as the provision of access to social networks or teleconferences, is related to the culture of the organisation. The organisational culture is also the main promoter of the perception of loss of power, influence or privileged work position over other elements of the organisation when sharing the knowledge that is a detector. The privilege of stopping rare knowledge and the association thereof to an increase in power, rather than a matter of organisational structure or individual perception, of something culturally instituted in the organisation. Although tacit knowledge is focused on people, it is the current organisational culture that determines the focus on their transmission or sharing. The strategies to be adopted for this purpose, rather than individual preferences or impositions of the organizational structure, are rooted in the organizational culture, since it privileges the interaction between the people who compose it, the focus will focus on dialogue and interaction, rather than coding and storage for later knowledge consultation..

Reward and recognition by sharing tacit knowledge rather than being decreed by organisational structure is considered to be part of organisational culture. The individual motivation that this exerts on the elements of the organisation makes include this indicator as influential in the factor relative to the individual characteristics. However, for the recognition and encouragement that can occur between peers reveals that the organisational culture is determinant for the individual sensation of recognition and reward for the sharing of tacit knowledge. The type of specialized training that promotes the acquisition of skills and tacit knowledge to perform tasks can be "enacted" by the organisational structure; however, their prevalence as part of the organisational culture is highly conducive to sharing tacit knowledge. The adoption of processes 
such as mentoring or coaching is revealing of the importance that the organisation attributes to the type of training aimed at this tacit knowledge sharing.

The second factor found is "individual characteristics", composed of a set of indicators referring to individual characteristics, innate to the person who belongs to an organisation. Thus, it can be said that the capacity of the person to create and feel a sense of mutual trust between individuals favours the sharing of tacit knowledge. The sense of diminishing risks and uncertainties in tacit knowledge sharing is smaller, the greater the individual's ability to establish stable, secure and trustworthy relationships among individuals. In this exercise of tacit knowledge sharing, and because the greater the tacit experience, the greater the difficulty of verbalization, the greater the importance of using a common language. It is important that the sender and the receiver are in tune, since they are highly individualized and personalized knowledge sharing experiences, being dependent on the intervening to adopt a language where both use the same terminology or expressions. Since time is an increasingly scarce resource within organisations and how sharing tacit knowledge can be time consuming, what each element does with its available time is increasingly an individual option. It is not a question here of checking whether the elements have more or less time available, but rather what each one does with the free time they have in an organisational context, which can be channelled to tacit knowledge sharing, but rather much depends on the individual decision made.

Within an organisation there are always elements that hold a greater source of tacit knowledge than others. Both from the perspective of those who have this knowledge and from the perspective of those who seek it, the network of relationships to which each element has access is determinant for this sharing to be done most effectively. Both the issuer and the receiver of this knowledge may not know who has or who needs this knowledge, something that the organisational structure can promote, fostering the approximation of the parts. However, the starting point for this process should come from an individual impulse to seek tacit knowledge or an impulse to share it, later supported by the organization's internal network.

Although it is the organisational culture to foster an environment of reward and recognition for the sharing of tacit knowledge, it is only effective if it finds echo in what the individual expectations intrinsic to the person. What can serve as an incentive or reward for one person can have a counterproductive effect for another, so it is an exercise that facilitates the sharing of tacit knowledge, but which is based on the intrinsic characteristics of the individual.

The third factor found is "organisational structure". As far as their organisational structure is concerned, these organisations operate under paramilitary logics, where the hierarchy is quite present in a pyramidal form, bureaucracy and formality can act as an obstacle to the sharing of tacit knowledge. This style of structure favours behaviours that discourage exchanges of experience and tacit knowledge, since the elements, rather than seeking to achieve the goals of the organisation, may seek to achieve their own goals. The strong presence of a hierarchy leads to a reduction of time, flexibility and a willingness to inform, ideal for sharing tacit knowledge.

In addition to the individual use that each element can make of the relationship network at its disposal, it is important to mention that this indicator is also present in the organisational structure, since the relationship network, leaves which is potentially impaired by the departure of the hierarchy, so that the elements of the hierarchical pyramid base do not have as much access to the elements that make up the top of the pyramid as potentially more tacit knowledge and which could contribute to the more effective sharing of tacit knowledge. Through the organisational structure, this network of relationships does not favour the sharing of tacit knowledge. More than the individual will or the organisational culture, it is the organisational structure that is responsible for orienting the focus of knowledge storage in databases that promote the sharing of explicit knowledge, or in people, promoting the sharing of tacit knowledge. In this case, a strategy oriented to the storage of knowledge in people themselves presupposes a high level of personalization of knowledge, is privileging and promoting the sharing of tacit knowledge. It is the responsibility of the organisational structure to implement strategies aimed at sharing tacit knowledge and promoting a specific type of training for the task, such as mentoring and coaching. The adoption of strategies that provide for the exchange of experience of elements with greater tacit knowledge with others more inexperienced or who come back to the organisation is something that is within the reach of the organisational structure. Its implementation reveals the importance that the organisation gives to the sharing of tacit knowledge. Although the transmission of knowledge is closely linked with the organisational culture, it is the organisational structure that promotes the conditions for this transmission to occur effectively. If the 
organisational structure option rests on the adoption of strategies aimed at contact between people, where tacit knowledge is fostered, on the other hand, if the organisational structure promotes strategies that rely on the re-use of codified knowledge, there will be no great interaction between people, but between people and technology, so the focus is centred on the explicit sharing of knowledge.

In this way, it is possible to elaborate a schematic representation for a better interpretation of the results regarding the indicators and factors with influence on the tacit knowledge sharing, according to figure 2.

Figure 2. Indicators and tacit knowledge sharing factors in FBs.

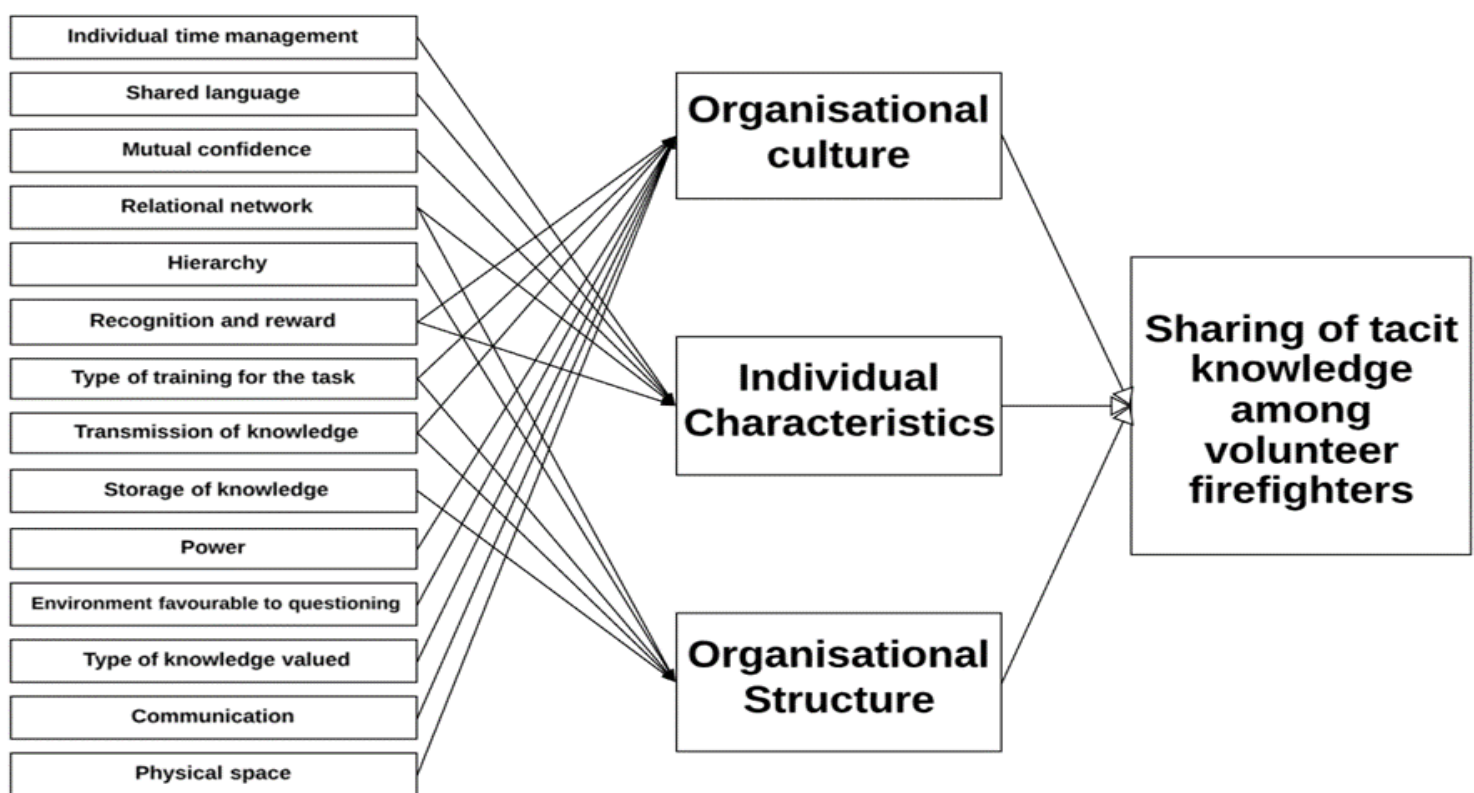

Source: By the authors

\subsection{Barriers to tacit knowledge sharing in FBs}

After completing the factorial analysis of the data obtained through the responses to the questionnaires by the firemen, regarding the barriers to tacit knowledge sharing, it was possible to find 4 types of barriers most prevalent in these organisations, according to table 3 . These barriers also find correspondence in the testimonies collected in the interviews conducted.

Table 3. Rotated matrix component of barriers to tacit knowledge sharing in FBs.

\begin{tabular}{|c|c|c|c|c|c|c|c|c|c|c|}
\hline \multirow[t]{2}{*}{ Barriers } & \multicolumn{10}{|c|}{ Components } \\
\hline & 1 & 2 & 3 & 4 & 5 & 6 & 7 & 8 & 9 & 10 \\
\hline $\begin{array}{l}\text { Insufficient } \\
\text { communication }\end{array}$ or $\quad$ non-existent & ,731 & & & & & & & & & \\
\hline Internal competitiveness & ,712 & & & & & & & & & \\
\hline Hierarchical structure & ,702 & & & & & & & & & \\
\hline Lack of benefit communication & 679 & & & & & & & & & \\
\hline Size of organisation &, 570 & & & & & & & & & \\
\hline Need for cultural change &, 511 & & & & & & & & & \\
\hline Low retention rate of knowledge &, 508 & & & & & & & & & \\
\hline Different levels of experience &, 441 & & ,439 & & & & & & & \\
\hline Shortage of time for contacts &, 437 & & & & & & & & & \\
\hline IT inadequate to internal communication & &, 807 & & & & & & & & \\
\hline IT inadequate to the needs & &, 800 & & & & & & & & \\
\hline Insufficient technical support & &, 770 & & & & & & & & \\
\hline Insufficient IT & &, 758 & & & & & & & & \\
\hline $\begin{array}{l}\text { IT with no potential for better } \\
\text { performance }\end{array}$ & & ,692 & & & & & & & & \\
\hline IT difficult to use & &, 545 & & & & & & & & \\
\hline Different cultural origins & & & ,802 & & & & & & & \\
\hline Different genres & & & ,770 & & & & & & & \\
\hline Different levels of schooling & & &, 571 & & & & & & & \\
\hline
\end{tabular}




\begin{tabular}{|c|c|c|c|c|c|c|c|c|}
\hline Different generations or ages & ,530 & & & & & & & \\
\hline Different languages & , 481 & & & & & & & \\
\hline Information overload & & ,719 & & & & & & \\
\hline Extra and intrusive activity & & ,703 & & & & & & \\
\hline What I do leads to the absence of sharing & & ,496 & & & & & & \\
\hline Time to meet needs & & & ,863 & & & & & \\
\hline Time to share & & &, 858 & & & & & \\
\hline I do not recognize advantages & & & & 660 & & & & \\
\hline Lack of recognition and reward & & & & 605 & & & & \\
\hline I do not like other FBs copies & & & & & ,709 & & & \\
\hline Trust in the knowledge of others & & & & & 437 & & & \\
\hline Lack of access to social networks & & & & & & ,763 & & \\
\hline $\begin{array}{l}\text { Privilege to physical and documentary } \\
\text { support }\end{array}$ & & & & & & ,576 & & \\
\hline $\begin{array}{l}\text { Incompatible with organisation } \\
\text { objectives }\end{array}$ & & & & & & ,409 & & \\
\hline Strong sense of hierarchical structure & & & & & & &,- 593 & \\
\hline I'm afraid to share & & & & & & &, 516 & \\
\hline Difficulty interpersonal relationship & & & & & & & ,497 & \\
\hline Lack of resources and infrastructures & & & & & & & & ,834 \\
\hline
\end{tabular}

Source: By the authors

The first type of barriers identified in the study are the communication barriers included in component 1. The first communication barrier identified in the present study is insufficient or non-existent communication. Communication is fundamental to the organisation, as Davenport and Prusak (1998) refer. These authors tell us that communication may have a verbal or written nature, whereas Riege (2005) tells us that personal interactions are fundamental for tacit knowledge sharing, so the lack of communication that places the actors in interaction, proves to be a very important barrier. Internal competitiveness within the FBs can also be considered a barrier to this sharing, since the structure of the organisation is based on a paramilitary logic, pyramidal, formal and relatively bureaucratic and not flexible. In these contexts where internal competitiveness is enhanced in view of career progression, it is relatively easy to determine the prevalence of a barrier of this type.

Following these considerations, another barrier naturally arises based on the hierarchical structure. In this particular point, it should be noted that the distance between the top and the bottom of the hierarchical structure of the FBs promotes a separation between people, which usually corresponds to those with greater experience and less tacit knowledge. This distance leads to less communication, or even to its absence, which in many cases undermines the sharing of tacit knowledge. The lack of communication of the benefits of tacit knowledge sharing is another communication barrier that the present study was able to ascertain. It is the responsibility of the organisation's management or administration to communicate that the objectives or strategies go through the adoption of tacit knowledge-sharing practices, their advantages and their respective forms of reward and recognition. The lack of this effective communication to subordinates rises as a barrier to the sharing of tacit knowledge. The size of the organisation or functional departments, when too large, can hamper tacit knowledge sharing activities. In the centre of FBs we find organisations of different dimensions, so the present barrier makes sense even though we have not ascertained what FBs are small, medium and large.

The need for cultural change is another barrier that we find in the present study. The culture of an organisation can be compared to its spirit and that which emanates from that spirit and that leads to the fulfilment of the mission, whether through the focus on customer satisfaction, profit making, betting in research and development, among others. In a tacit knowledge-sharing sharing logic, where communication is determinant, the need for cultural change within the FBs is to provide these organisations with a communicational culture that can mitigate or eliminate this barrier that was clearly identified in the present study. The low knowledge retention rates of the most experienced elements were another communication barrier identified in this study. All organisations have elements that hold more experience or tacit knowledge. Whenever there is a prolonged absence or withdrawal from these elements of the organisation to which they belong, it is a great source of tacit knowledge that is no longer available or is hopelessly lost. timely adoption of communication strategies can avoid these unreliable scenarios to tacit knowledge sharing. 
The coexistence of people with different levels of experience can be considered as an obstacle to the sharing of tacit knowledge, since it may prevail for the more experienced, the feeling that it is not relevant to communicate with the less experienced, as they may not understand the message, or even if communication is established, the less experienced will be able to have the same level of knowledge as the more experienced, questioning its importance within the organisation. This was a clearly identified barrier for the FBs. The last communication barrier identified was the shortage of time to establish contacts and increase the relationship between people, although the managers of the organisation alert the need and the benefits of tacit knowledge sharing, the shortage of time that the employees have for the most different tasks leads them to choose to do immediately what can be translated into a visible or palpable result for the organisation, which takes into account the prerequisites ideal for an effective sharing of tacit knowledge. The relationship between people and the constitution of a relationship network, even if informal, is fundamental for communication to flow and thus combat this barrier that is also present in FBs.

The second type of barriers identified in the study are the technological barriers included in component 2 . This type of barriers is composed of the following barriers: inadequate information technologies for internal communication, inadequate information technologies, insufficient technical support and insufficient information technologies. In relation to these types of barriers, we can see that they may be inadequate, both for internal communication within FBs and for their needs in general, and that these are barriers that are found in the literature. The possibility of poor technical support is another technological barrier, which is also echoed in this study. Insufficient and difficult to use technology, with no potential for improving the performance of firefighters are other barriers pointed out by Riege (2005) whose prevalence is verified in this type of organization.

The third type of barriers identified in the study are personal barriers, which is based on the individual characteristics of the people who make up the organisation, their perceptions, feelings or preferences. In the present study it was possible to find 6 subtypes of personal barriers: individual differences (component 3 ), individual perception of sharing costs (component 4), lack of time (component 5), recognition and reward (component 6), vision of others component 7) and preference for explicit knowledge (component 8).

Thus, the first subtype of personal barriers are the personal differences that are based on different cultural origins, genres, levels of education, generations or ages, languages and levels of experience. In this regard, it should be noted that these personal barriers are echoed in the literature, since for McDermott and O'Dell (2001) there are several studies that point out the different cultural origins as barriers to the sharing of tacit knowledge, since they are responsible for giving the person a set of values, principles, practices or symbologies, not necessarily consistent with those practiced in the organisation. Sveiby and Simmons (2002) also point out differences in gender, schooling or generation or age as the focus of potential barriers, as they may be responsible for providing people with different expectations, attitudes, postures or commitment to the organisation. the organisational context may not correspond to everyone in the same way.

In terms of different languages, but according to the business context, we can consider the contributions of Terpstra and David (1991), who tell us that these differences may also restrict the sharing of tacit knowledge, but that the present study also found together of FBs. Regarding different levels of experience, Riege (2005) also refers to this as a potential barrier in an organisational context, since individual experience interferes with individual expectations that do not necessarily have to be compatible with the expectations of the rest of the organisation.

The second subtype of personal barriers is the individual perception of the costs of tacit knowledge sharing, since this sharing can be seen as an overload of information, be considered as an extra or intrusive activity or make pass the sensation that what the person does nothing to contribute to the sharing of tacit knowledge and thus to abandon the efforts leading to this sharing. If there is no specific focus of the organisation on the sharing of what is tacit knowledge, easily the vicissitudes of the functions that people perform lead them to choose a more accessible and immediate knowledge, starting to consider what is tacit as something extra, secondary or even intrusive and an information overload, not essential for the good performance of its functions. Once again, this barrier has also been identified within the FBs. 
The third subtype of personal barriers is the lack of time, either for sharing tacit knowledge or for identifying who needs to receive this knowledge.

The fourth subtype of personal barriers is recognition and reward, in the sense that the poor perception of advantages in sharing tacit knowledge and the reduced realization that the effort at this sharing is not recognized or rewarded by the organisation can lead to the abandonment of these practices.

The fifth subtype of personal barriers is the view of others, since according to personal characteristics, each element of the organisation may have greater or lesser pleasure or satisfaction in seeing its replicated knowledge, either by other elements of the same organisation, or by elements of other organisations. Likewise, the sense of trust that each element has in relation to what others transmit to it can also constitute an important barrier to the sharing of tacit knowledge.

The sixth subtype of personal barriers to tacit knowledge sharing is the preference for explicit knowledge, either by giving priority to social networks or other physical media, in documentary or other forms of distance communication, which reduces personal contact and the interaction by which tacit knowledge is transmitted, or because it is ultimately considered that this sharing is not in line with the organisation's objectives.

The fourth and last type of barriers identified in the study is the resource and infrastructure barriers included in components 9 and 10. This type of barriers is composed of two subtypes of barriers: presence of formal sense and structure (component 9) and resources physical and material (component 10).

The first subtype of barriers affecting resources and infrastructures is composed of the following barriers: strong sense of hierarchical structure, fear of sharing and difficulty of interpersonal relationship. Regarding the presence of formal meaning and structure, it is important to mention that this is one of the reasons why there is some fear of sharing tacit knowledge by firefighters, since according to De Long and Fahey (2000) one can be in front of where there is not much tolerance of the superiors towards the error of the subordinates, having little space for learning through mistakes or lessons learned. The FBs are organisations that build their internal organisation in a strong presence of formal sense and pyramidal hierarchical structure, under logics of paramilitary functioning, that in a way promote the distance between people and that provide greater difficulties of interpersonal relationship, namely between elements of different levels of hierarchy.

The second subtype of resource and infrastructure barriers is the physical or material barrier, which is also reported in the literature by Probst et al (2000) and Gold et al. (2001) and also in the FBs, since these physical spaces or material ideas to create an environment conducive to the sharing of tacit knowledge is seen as being far from ideal. In FBs this barrier is verified essentially to the level of the inadequacy of the functional areas and to the absence of suitable conditions for learning through training of competences.

In this way, it is possible to elaborate a schematic representation for a better interpretation of the results regarding the barriers with tacit knowledge sharing, according to figure 3 .

Figure 3. Barriers to tacit knowledge sharing in FBs. 


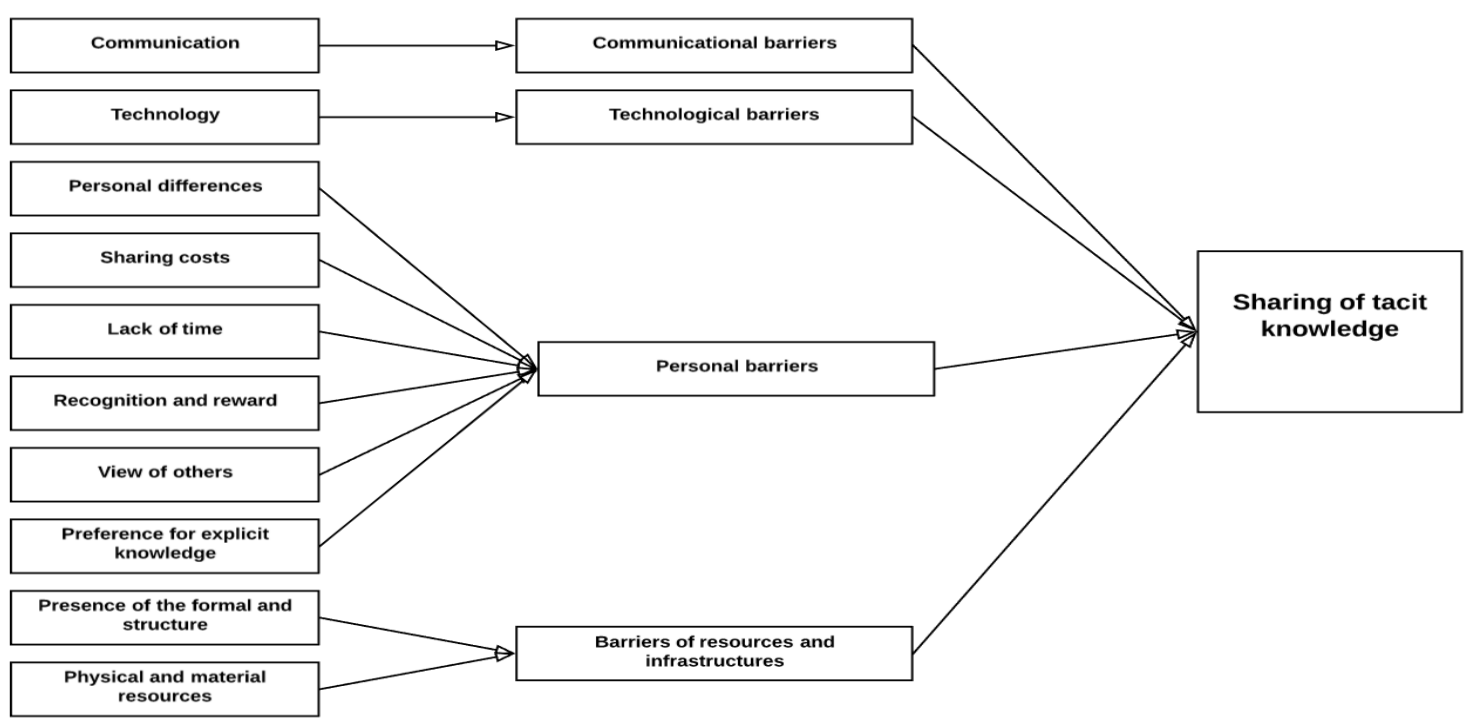

Source: By the authors

\section{CONCLUSIONS AND RECOMMENDATIONS}

Taking into consideration the objectives of the study, it can be concluded that the tacit knowledge sharing indicators are relevant in at least one factor of this sharing, even though the indicators 4 - relationship network, 6 - recognition and reward, 7 - type of training for the task and 8 - transmission of knowledge, are relevant in two of the three factors found. Through the factorial analysis, it is possible to conclude that the 14 indicators can be grouped into 3 factors which influence tacit knowledge sharing, according to figure 2 .

It is also possible to conclude that the barriers to knowledge sharing in the organisations studied are of four different types: communicational, technological, personal and resource barriers or infrastructures, and it is possible to identify within the personal barriers 6 subgroups of barriers (personal differences, costs of sharing, lack of time, recognition and reward, vision of others and preference for explicit knowledge), as well as within the typology of resources and infrastructures, and it is possible to identify two subgroups of barriers (presence of formal meaning and structure and resources physical or material). Figure 3 shows how barriers are grouped into types and subtypes.

The present study thus contributes to theoretical advances since it was possible to confirm the applicability of indicators and barriers to the sharing of tacit knowledge already identified in the literature, although originally associated with private sector and public sector organizations and based on these contributions, the practice of advancing with a matrix of action in combating the most prevalent types of barriers to sharing this type of knowledge.

For future work, and since we are dealing with non-profit organisations, it is recommended that a study be carried out to evaluate the impact of this knowledge sharing on organisational performance, especially with regard to the fulfilment of its missions. It is also suggested to carry out studies that aim to present solutions to better overcome the barriers identified in these NPOs.

\section{REFERENCES}

Awad, E. and Ghaziri, H. (2007). Knowledge management. Delhi: Pearson Education. 
Castellani, P., Rossato, C. and Giareta, E. (2019). Tacit knowledge sharing in knowledge-intensive firms: the perceptions of team members and team leaders. Review of Managerial Science, https://doi.org/10.1007/s11846-019-00368-x

Cross, R. et al. (2001). Knowing what we know: supporting knowledge creation and sharing in social networks. Organizational Dynamics, v. 30, n. 2, p. 100-120. http://dx.doi.org/10.1016/S00902616(01)00046-8

Dalkir, K. (2005). Knowledge Management in Theory and Practice, Boston: Elsevier.

Davenport, T.H. and Prusak, L. (1998), Working Knowledge: How Organisations Manage what they Know, HBS Press, Boston, MA.

Davenport, T. and Prusak, L. (1998). Working knowledge: How Organizations Manage What They Know. Boston, Massachusetts: Harvard Business School Press.

De Long, D. and Fahey, L. (2000). Diagnosing cultural barriers to knowledge management. The Academy of Management Executive, Vol. 14 No. 4, pp. 113-27.

Disterer, G. (2003). Fostering knowledge sharing: why and how? In: IADIS INTERNATIONAL CONFERENCE E-SOCIETY, 2003, Lisbon.

Eppler, M. and Sukowski, O. (2000). Managing team knowledge: core processes, tools and enabling factors. European Management Journal, Vol. 18 No. 3, pp. 334-341.

Fahey, L. and Prusak, L. (1998). The eleven deadliest sins of knowledge management. California Management Review, v. 40, n. 3, p. 265-276.

Fotler, M. (1981), “Is management really generic?”, Academy of Management Review, 6(1), pp. 1-12.

Gold, A., Malhotra, A. and Segars, A. (2001). Knowledge management: an organizational capabilities perspective. Journal of Management Information Systems, Vol. 18 No. 1, pp. 185-214.

Haldin-Herrgard, T. (2000). Difficulties in the Diffusion of Tacit Knowledge in Organizations. Journal of Intellectual Capital, 1(4): 357-365.

Hansen, M. Nohria, N. and Tierney, T. (1999). What's your strategy for managing knowledge? Harvard Business Review, p.1-10.

Holste, J. and Fields, D. (2010). Trust and tacit knowledge sharing and use, Journal of Knowledge Management, Vol. 14 Issue: 1, pp.128-140, https://doi.org/10.1108/13673271011015615

Ichijo, K., Krogh, G. and Nonaka, I. (1998). Knowledge enablers, in G. Krogh, J. Roos, and D. Kleine (Eds.), Knowing in Firms: Understanding, Managing and Measuring Knowledge, Sage Publications, Thousand Oaks, California, pp. 173-203.

Jeng, D. and Dunk, N. (2013). Knowledge management enablers and knowledge creation in ERP system success. International Journal of Electronic Business Management, Vol. 11 No. 1, pp. 49-59.

Jóia, L. (2007). Knowledge Management Strategies: Creating and Testing a Measurement Scale. International Journal of Learning and Intellectual Capital, v. 4, n. 3, p. 203-221. http://dx.doi.org/10.1504/IJLIC.2007.015607

Joia, L. and Lemos, B. (2010). Relevant factors for tacit knowledge transfer within organisations. Journal of Knowledge Management, vol. 14, pp. 410-427, 2010.

Lemos, B. and Jóia, L. (2012). Relevant factors for tacit knowledge transfer within organizations: an exploratory study. Gestão \& Produção, v. 19, n. 2, p. 233-246.

Leonhard, D. and Sensiper, S. (1998). The role of tacit knowledge in group innovation. California Management Review, 40(3):112-25. 
McDermott, R. (1999). Why information technology inspired but cannot deliver knowledge management. California Management Review, Vol. 41 No. 4, pp. 103-17.

Michailova, S. and Husted, K. (2003). Knowledge-sharing hostility in Russian firms. California Management Review, Vol. 45 No. 3, pp. 59-77.

Mohajan, H. (2016). Sharing of tacit knowledge in organizations: A Review. American Journal of Computer Science and Engineering, 3(2), 6-19.

Nonaka, I. (1994). A dynamic theory of organizational knowledge creation. Organization Science, 5(1): 14-37.

Nonaka I. and Takeuchi H. (1995). The knowledge creating company: how Japanese companies create the dynamics of innovation. Oxford: Oxford University Press.

O’Dell, C. and Grayson, C. (1998). If only we knew what we know: identification and transfer of internal best practices. California Management Review, v. 40 n. 3, p. 154-174

Oliveira, M. and Pinheiro, P. (2019). Factors in the sharing of tacit knowledge among volunteer firefighters. International Journal of Business and Management. DOI:10.5539/ijbm.v14n9p54

Polanyi, M. (1962). Tacit knowing: its bearing on some problems of philosophy. Knowing and being: essays by M. Polanyi. London: Routledge and Keagan.

Polanyi, M. (1966). The tacit dimension. Chicago: University of Chicago Press.

Probst, G., Raub, S. and Rombhardt, K. (2000). Managing Knowledge, John Wiley \& Sons, Chichester.

Ragsdell, G. (2016), “Knowledge Management in the Not-For-Profit Sector: Introduction”, Journal of Knowledge Management, ISSN: 1758-7484. DOI: 10.1108/JKM-11-2015-0483.

Riege, A. (2005). Three-Dozen Knowledge-Sharing Barriers Managers Must Consider. Journal of Knowledge Management, 9(3):18-35.

Riege, A. (2007). Actions to overcome knowledge transfer barriers in MNCs. Journal of Knowledge Management, vol. 11, no. 1, pp.48-67.

Sohi, R. S. and Matthews, A. L. (2019). Organizational learning and inter-organizational knowledge transfer. Handbook of Research on Distribution Channels, 114.

Sun, P. and Scott, J. (2005). An investigation of barriers to knowledge transfer. Journal of Knowledge Management, v. 9, n. 2, p. 75-90, 2005. http://dx.doi.org/10.1108/13673270510590236

Sveiby, K. (1997). The new organizational wealth: managing and measuring knowledge- based assets, Berrett-Koehler, San Francisco.

Sveiby, K. and Simons, R. (2002). Collaborative climate and effectiveness of knowledge work. Journal of Knowledge Management, Vol. 6 No. 5, pp. 420-33.

Szulanski, G. (1996). Exploring Internal stickiness: impediments to the transfer of best practice within the firm. Strategic Management Journal, v. 17, p. 27-43.

Terpstra, V. and David, K. (1991). The Cultural Environment of International Business, 3rd ed., SouthWestern Publishing, Cincinnati, $\mathrm{OH}$.

Young, M. (2010). Why educators must differentiate knowledge from experience? Journal of the Pacific Circle Consortium for Education, v. 22, n. 1, p. 9-20. 